\title{
Cytolytic and Phospholipase C Activity in Legionella Species
}

\author{
By WILLIAM B. BAINE \\ Departments of Internal Medicine and Microbiology, Southwestern Medical School and \\ Southwestern Graduate School of Biomedical Sciences, The University of Texas Health Science \\ Center at Dallas, 5323 Harry Hines Boulevard, Dallas, Texas 75235, USA
}

(Received 6 September 1984; revised 10 December 1984)

To examine one possible mechanism of damage to leucocytes and tissue cells in legionellosis, seven species of Legionella were examined for cytolytic activity and for elaboration of phospholipase $C$, an enzyme that can damage mammalian cell membranes. Cytolysis was assessed using erythrocytes in agar. Phospholipase $\mathrm{C}$ was assayed by release of $p$-nitrophenol from $p$-nitrophenylphosphorylcholine and of tritiated phosphorylcholine from $\mathrm{L}-\alpha$-dipalmitoyl[choline-methyl- ${ }^{3} \mathrm{H}$ ]phosphatidylcholine. L. pneumophila, L. bozemanii, L. micdadei, L. dumoffii, $L$. gormanii, L. longbeachae and $L$. jordanis all lysed dog red blood cells, which have a high ratio of membrane phosphatidylcholine to sphingomyelin. The same strains hydrolysed varying amounts of $p$-nitrophenylphosphorylcholine; $L$. bozemanii exhibited the greatest activity. $L$. pneumophila, $L$. bozemanii, $L$. dumoffii, $L$. longbeachae and $L$. jordanis, but not $L$. micdadei, released tritiated phosphorylcholine from labelled substrate. These results indicate that several species of Legionella possess cytolytic capability; exotoxins with phospholipase C activity may play a role.

\section{INTRODUCTION}

Legionella pneumophila and other species of Legionella are aetiologic agents of pneumonia in man (Meyer, 1983). Despite rapid progress since 1976 in delineating the epidemiology and clinical manifestations of legionellosis, much remains to be learned about the mechanisms of pathogenesis at the tissue and cellular levels in Legionella infections.

Many pathogenic bacteria elaborate cytolysins - exotoxins that damage host-cell membranes in vitro (Alouf, 1977). In certain bacterial infections some of these cytolytic toxins may also play a role in pathogenesis in vivo. Cultures of $L$. pneumophila lyse mammalian erythrocytes in agar medium (Baine et al., 1979a). Guinea-pig erythrocytes, in which the cell membrane has a high ratio of phosphatidylcholine to sphingomyelin, are particularly susceptible (Baine et al., 1979a). Cultures of $L$. pneumophila also produce an opaque zone in agar medium containing egg yolk (Baine et al., 1979a), a reaction resembling that produced by Clostridium perfringens on egg-yolk agar and attributed to clostridial $\alpha$-toxin (Smith et al., 1980). The $\alpha$-toxin is a phospholipase $C$ (EC 3.1.4.3), which hydrolyses phosphatidylcholine to 1,2-diacylglycerol and phosphorylcholine (Möllby, 1978).

This report extends earlier observations on haemolytic activity and digestion of egg yolk exhibited by L. pneumophila to six additional species of Legionella and assesses phospholipase C activity in Legionella species by means of specific biochemical assays. In the present study haemolysis, digestion of egg yolk and phospholipase $\mathrm{C}$ activity are evaluated using Legionella cultures or suspensions of bacterial cells as a prelude to future attempts to purify the putative toxins and enzymes from culture supernates or lysates.

Abbretiations: BYE, buffered yeast extract medium; ABYE, augmented BYE; DBYE, dialysed BYE. 


\section{METHODS}

Bacterial strains. Representative strains of $L$. pneumophila serogroups 1 (Philadelphia 1, Pontiac 1), 4 (Rockport 1), 5 (Dallas IE) and 6 (Chicago 2), L. bozemanii serogroup 1 (Wiga), L. micdadei (PI-1), L. dumoffii (NY-23), L. gormanii (LS-13), L. longbeachae serogroups 1 (Long Beach 4) and 2 (Tucker 1), and L. jordanis (BL-540) were obtained from the Centers for Disease Control, Atlanta, Ga., USA, and maintained by serial passage on buffered charcoal/yeast extract agar (Feeley et al., 1979; Pasculle et al., 1980).

Media. Buffered yeast extract (BYE) medium contained $1 \%(\mathrm{w} / \mathrm{v})$ yeast extract, $1 \%(\mathrm{w} / \mathrm{v})$ ACES, $0.040 \%(\mathrm{w} / \mathrm{v})$ L-cysteine hydrochloride and $0.025 \%(\mathrm{w} / \mathrm{v})$ soluble ferric pyrophosphate and was adjusted to $\mathrm{pH} 6.9$ with potassium hydroxide (Pasculle et al., 1980). Augmented buffered yeast extract (ABYE) medium was BYE supplemented with $0.5 \%(\mathrm{w} / \mathrm{v})$ potassium 2-oxoglutarate and $1 \%(\mathrm{w} / \mathrm{v})$ bovine serum albumin (Cohn's fraction V). Dialysed buffered yeast extract (DBYE) medium was BYE in which a dialysate of $10 \mathrm{~g}$ yeast extract per litre of medium was substituted for yeast extract powder. Solid media contained $1.7 \%(w / v)$ agar.

Haemolysis. Blood agar plates were prepared with $5 \%$ sterile defibrinated blood as previously described (Baine et al., 1979a). Cultures were examined daily after inoculation, and the extent of haemolysis was graded semiquantitatively from - (absent) to ++++ (extensive).

Digestion of egg yolk and lecithin. Egg-yolk agar contained $5 \%(\mathrm{v} / \mathrm{v})$ sterile hen's egg yolk as previously described (Baine et al., 1979a). Lecithin agar contained L- $\alpha$-phosphatidylcholine from fresh-frozen egg yolk (type IX-E, approximately $60 \%$ pure; Sigma), which was dispersed by vortexing the molten autoclaved medium just before it was dispensed into Petri dishes. Plates were incubated at $35^{\circ} \mathrm{C}$ and examined daily after inoculation for the development of superficial iridescence of the culture, and for the appearance of zones of translucent clearing and an opaque precipitate within the medium, suggesting the activity of lipase, protease and lecithinase (phospholipase C), respectively (Allen \& Siders, 1980). These changes were graded semiquantitatively from (absent) to ++++ (extensive).

Hydrolysis of p-nitrophenylphosphorylcholine. Liberation of yellow $p$-nitrophenol from $p$-nitrophenylphosphorylcholine (Sigma), a water-soluble analogue of phosphatidylcholine, was used as a measure of phospholipase C activity (Kurioka \& Matsuda, 1976). In a qualitative plate assay, seven species of Legionella were inoculated on DBYE agar containing $19.6 \mathrm{mM}-p$-nitrophenylphosphorylcholine, and the cultures were incubated at $37^{\circ} \mathrm{C}$.

For a quantitative assay of phospholipase C activity, $250 \mathrm{ml}$ volumes of BYE broth in $1000 \mathrm{ml}$ Erlenmeyer flasks were inoculated with Legionella strains, and the cultures were incubated for $2 \mathrm{~d}$ at $37^{\circ} \mathrm{C}$ in a shaker bath with agitation at 180 r.p.m. After sedimentation $(13200 \mathrm{~g}, 10 \mathrm{~min})$ the packed cells were washed 3 times in $5.0 \mathrm{mM}$ Tris ( $\mathrm{pH} 7.2$ ), $2.0 \mathrm{~mm}-\mathrm{CaCl}_{2}$, and resuspended in $1.5 \mathrm{ml}$ volumes in the same buffer to give suspensions with a calculated optical density at $590 \mathrm{~nm}$ of 2.00 over a $1 \mathrm{~cm}$ light path (Bausch \& Lomb type 33-29-40 colorimeter). Equal $1.5 \mathrm{ml}$ volumes of the suspension of bacteria and of sterile $40 \mathrm{~mm}-p$-nitrophenylphosphorylcholine in the same buffer were mixed in screw-cap tubes and placed in a shaker bath which was operated at $37^{\circ} \mathrm{C}$ and 180 r.p.m. Control tubes containing bacteria without substrate, substrate without bacteria and buffer alone were processed in parallel. After overnight incubation, bacterial cells were sedimented by centrifugation, and hydrolysis of $p$-nitrophenylphosphorylcholine was assayed by measuring the absorbance of the supernates at $410 \mathrm{~nm}$ with correction for absorbance in control tubes. The concentration of the liberated chromophore was calculated with a programmable calculator from standard absorption curves prepared from solutions of $p$ nitrophenol at known concentrations.

The specificity of the method was assessed with commercially supplied phospholipases $\mathrm{C}$ and D. C. perfringens phospholipase C (type I, 8.1 $\mathrm{U} \mathrm{mg}^{-1}$ ), peanut phospholipase D (types II, $85 \mathrm{U} \mathrm{mg}^{-1}$, and III, $155 \mathrm{U} \mathrm{mg}^{-1}$ ), and cabbage phospholipase D (type IV, $90 \mathrm{U} \mathrm{mg}^{-1}$ ) were obtained from Sigma. Solutions of these enzymes at final concentrations of $6.5 \mathrm{U} \mathrm{ml}^{-1}, 36 \mathrm{U} \mathrm{ml}^{-1}, 120 \mathrm{U} \mathrm{ml}^{-1}$ and $81 \mathrm{U} \mathrm{ml}^{-1}$, respectively, were incubated overnight at $37^{\circ} \mathrm{C}$ in $200 \mu \mathrm{l}$ mixtures containing $20 \mathrm{mM}$-p-nitrophenylphosphorylcholine in $0.1 \mathrm{M}$-Tris (pH 7.65), $7.0 \mathrm{mM}$ $\mathrm{CaCl}_{2}, 3.0 \mathrm{mM}-\mathrm{NaN}_{3}$. The absorbance of each mixture at $410 \mathrm{~nm}$ was measured after addition of $2.0 \mathrm{ml}$ distilled water to each tube. The concentration of $p$-nitrophenol was determined as previously described and expressed as mmol liberated per unit of phospholipase C or phospholipase D activity, as appropriate.

Hydrolysis of tritiated lecithin. Phospholipase $\mathrm{C}$ activity in Legionella was assayed directly by a modification of the procedure of Grossman et al. (1974) using lecithin labelled with tritium in the methyl groups of the choline moiety. Legionella strains were grown in BYE broth and harvested as described above. Sedimented bacterial cells were washed three times in sterile distilled water and resuspended in distilled water to give suspensions with a calculated optical density of 15.0 at $590 \mathrm{~nm}$ over a $1 \mathrm{~cm}$ light path. L- $\alpha$-Dipalmitoyl[choline-methyl- $\left.{ }^{3} \mathrm{H}\right] \mathrm{phospha-}$ tidylcholine (specific activity $27 \mathrm{Ci} \mathrm{mmol}^{-1}$; New England Nuclear) was dispersed in $0.1 \mathrm{M}$-Tris (pH 7.65), $3.5 \mathrm{mM}-\mathrm{CaCl}_{2}, 0.16 \%(\mathrm{v} / \mathrm{v})$ Triton X-100, and sterilized by membrane filtration. Unlabelled $\mathrm{L}$ - $\alpha$-dipalmitoylphosphatidylcholine (Sigma) was dispersed in 0.1 M-Tris ( $\mathrm{pH} 7.65), 3.5 \mathrm{mM}-\mathrm{CaCl}_{2}, 0.16 \%(\mathrm{v} / \mathrm{v})$ Triton X-100, sterilized by autoclaving, and stored at $-20^{\circ} \mathrm{C}$; the unlabelled lecithin was sonicated (sonicator cell disruptor, model W185F, Heat Systems-Ultrasonics, Plainview, NY, USA) immediately before use to maximize dispersion of micelles. The final reaction mixtures contained $1.0 \mathrm{ml}$ Legionella suspension or sterile distilled water, $0.1 \mu \mathrm{Ci}$ 
tritiated lecithin $\mathrm{ml}^{-1}, 1.4 \mathrm{~mm}$-unlabelled lecithin, $71 \mathrm{mM}$-Tris (pH 7.65), $2.5 \mathrm{mM}-\mathrm{CaCl}_{2}$, and $0.11 \%(\mathrm{v} / \mathrm{v})$ Triton $\mathrm{X}-100$ in a total volume of $3.5 \mathrm{ml}$ in sterile screw-cap tubes.

After overnight incubation of the mixtures at $37^{\circ} \mathrm{C}$ with agitation at 180 r.p.m. or at $4{ }^{\circ} \mathrm{C}$ without agitation, the bacterial cells were sedimented, and $2 \mathrm{ml}$ volumes of the supernates were mixed with $0.57 \mathrm{ml} 6.0 \%(\mathrm{v} / \mathrm{v}) \mathrm{HClO}_{4}$ and $1 \mathrm{ml}$ distilled water. Portions $(2 \mathrm{ml})$ of the acidified samples were serially extracted with $10 \mathrm{ml}$ each of diethyl ether saturated with water, petroleum ether (boiling range $35-58^{\circ} \mathrm{C}$ ), and chloroform saturated with water to remove tritiated lecithin and choline (Gulewitsch, 1898; Renshaw, 1910), leaving phosphorylcholine in the acidified aqueous phase. Portions $(1 \mathrm{ml})$ of the extracted aqueous phase from each sample were then dispensed to vials containing $10 \mathrm{ml}$ liquid scintillation counting solution (Handifluor, Mallinckrodt, St Louis, Mo., USA), and the radioactivity present was determined by liquid scintillation counting (LS-330, LS-350 or LS-355 liquid scintillation system, Beckman Instruments). Radioactivity in the acidified aqueous phase of the samples containing distilled water blanks in place of Legionella suspensions was also determined without prior extraction with organic solvents. Phospholipase $\mathrm{C}$ activity was measured as the proportion of tritiated label released into the acidified aqueous phase as labelled phosphorylcholine as follows: [(c.p.m. in extracted Legionella sample) - (c.p.m. in extracted water blank)] $\times$ (c.p.m. in unextracted water blank $)^{-1}$.

The specificity of this assay for phospholipase $C$ depends upon quantitative extraction of free choline as well as intact lecithin from the acidified aqueous phase, leaving only labelled phosphorylcholine to be counted. If choline were not reliably extracted, the assay could not distinguish between phospholipase $C$ and phospholipase $D$, which hydrolyses lecithin at the bond between the phosphate group and the terminal choline moiety. The specificity of the method was verified with commercially supplied phospholipases $C$ and $D$ at the same concentrations used for validation of the colorimetric assay.

Enzyme solutions were incubated at $37^{\circ} \mathrm{C}$ in a final volume of $200 \mu \mathrm{l}$ in a tightly capped tube with $250 \mathrm{nCi} \mathrm{L-} \alpha$ dipalmitoyl[choline-methyl- $\left.{ }^{3} \mathrm{H}\right]$ phosphatidylcholine $\mathrm{ml}^{-1}, 1.0 \mathrm{mM}$-unlabelled $\mathrm{L}$ - $\alpha$-dipalmitoylphosphatidylcholine, $0 \cdot 1 \mathrm{~m}$-Tris ( $\mathrm{pH} 7.65), 7.0 \mathrm{~mm}-\mathrm{CaCl}_{2}, 3.0 \mathrm{mM}^{-\mathrm{NaN}_{3}}$, and $0 \cdot 11 \%(\mathrm{v} / \mathrm{v})$ Triton X-100. After overnight incubation the mixtures were brought to $2 \mathrm{ml}$ with $0 \cdot 11 \%(\mathrm{v} / \mathrm{v})$ Triton X-100 in distilled water. The samples were then acidified, diluted and extracted and the tritium label in the aqueous phase was measured as described above. Radioactivity in the acidified aqueous phase of blank samples without added enzyme was also determined without prior extraction with organic solvents. Phospholipase $\mathrm{C}$ activity was measured as previously described and expressed as nmol tritiated phosphorylcholine released into the acidified aqueous phase per unit of phospholipase $\mathrm{C}$ or phospholipase D activity.

\section{RESULTS}

Haemolysis

Ten strains of Legionella comprising L. pneumophila (Philadelphia 1, Pontiac 1, Rockport 1, Dallas 1E, Chicago 2), L. micdadei (PI-1), L. dumoffii (NY-23), L. longbeachae (Long Beach 4, Tucker 2) and $L$. jordanis (BL-540) grew on ABYE agar with rabbit blood after overnight incubation at $35^{\circ} \mathrm{C}$. The cultures exhibited various degrees of partial or complete haemolysis, which was first apparent after $2 \mathrm{~d}$ incubation and became progressively more distinct over the ensuing $2 \mathrm{~d}$. Haemolysis was most pronounced with the Dallas $1 \mathrm{E}$ strain of L. pneumophila and completely absent only with $L$. micdadei. Haemolysis was not enhanced by overnight refrigeration after $4 \mathrm{~d}$ at $35^{\circ} \mathrm{C}$ nor by a second passage on blood agar.

Eight strains of Legionella were grown at $35^{\circ} \mathrm{C}$ on ABYE agar with dog, guinea-pig, human, rabbit or sheep blood (Table 1). Dog red blood cells, with a high ratio of membrane phosphatidylcholine to sphingomyelin (Turner et al., 1958), were most susceptible to lysis. Red blood cells of rabbit, guinea-pig and sheep showed intermediate degrees of susceptibility. Haemolysis was slight to absent on human blood agar. L. micdadei produced no haemolysis except on dog blood agar. The seven other Legionella strains were definitely haemolytic, with $L$. pneumophila, $L$. bozemanii and $L$. longbeachae exhibiting the strongest activity.

ABYE dog blood agar plates were inoculated with the same eight strains and incubated at various temperatures. No specific enhancement of haemolysis was observed at incubation temperatures above or below $35^{\circ} \mathrm{C}$. No major influence of the composition of the basal medium on haemolysis by Legionella was apparent when the same eight strains were grown on dog blood agar made with ABYE, BYE and F-G media (Feeley et al., 1978). Divalent cations may variously enhance (Avigad, 1976) or diminish (Alouf, 1977) the activity of certain bacterial haemolysins. However, addition of $0.1 \mathrm{mM}-$ or $1.0 \mathrm{mM}-\mathrm{CaCl}_{2}$ or $\mathrm{ZnCl}_{2}$ to BYE dog blood agar had no apparent effect on haemolysis by the same eight strains of Legionella; supplementation with $10 \mathrm{mM}-\mathrm{CaCl}_{2}$ or $\mathrm{ZnCl}_{2}$ inhibited bacterial growth. 
Table 1. Haemolysis of red blood cells from five mammalian species by Legionella spp.

Cultures were incubated for $3 \mathrm{~d}$ on ABYE blood agar. The extent of haemolysis was graded from (absent) to +++ (extensive).

\begin{tabular}{|c|c|c|c|c|c|}
\hline \multirow[b]{2}{*}{ Species and strain } & \multicolumn{5}{|c|}{ Red blood cell source: } \\
\hline & Dog & $\begin{array}{l}\text { Guinea- } \\
\text { pig }\end{array}$ & Sheep & Rabbit & Human \\
\hline L. pneumophila (Philadelphia 1) & $+++\beta^{*}$ & + & + & ++ & + \\
\hline L. pneumophila (Dallas IE) & $+++\beta^{*}$ & ++ & ++ & $+t+t$ & + \\
\hline L. bozemanii (Wiga) & +++ & +++ & + & $++t+$ & + \\
\hline L. micdadei (PI-1) & ++ & - & - & - & - \\
\hline L. dumoffii (NY-23) & $+++\beta^{*}$ & + & + & ++ & \pm \\
\hline L. gormanii (LS-13) & $+++\beta^{*}$ & + & + & ++ & \pm \\
\hline L. longbeachae (Long Beach 4) & $++t$ & ++ & ++ & +++ & + \\
\hline L. jordanis (BL-540) & ++ & + & + & + & \pm \\
\hline
\end{tabular}

* Haemolysis progressed to yield a clear colourless zone around the bacterial growth, as with streptococcal $\beta$ haemolysis.

Table 2. Digestion of egg yolk by Legionella spp.

Cultures were incubated for $7 \mathrm{~d}$ on ABYE egg-yolk agar. The changes were graded from - (absent) to +++ (extensive).

\begin{tabular}{|c|c|c|c|}
\hline Species and strain & $\begin{array}{c}\text { Iridescence } \\
\text { (Lipase) }\end{array}$ & $\begin{array}{c}\text { Cleared } \\
\text { zones } \\
\text { (Protease) }\end{array}$ & $\begin{array}{c}\text { Opaque } \\
\text { precipitate } \\
\text { (Lecithinase) }\end{array}$ \\
\hline L. pneumophila (Philadelphia 1) & +++ & +++ & + \\
\hline L. bozemanii (Wiga) & +++ & +++ & +++ \\
\hline L. micdadei (PI-1) & - & - & - \\
\hline L. dumoffii (NY-23) & - & ++ & ++ \\
\hline L. gormanii (LS-13) & +++ & +++ & ++ \\
\hline L. longbeachae (Long Beach 4) & +++ & $+t+$ & ++ \\
\hline L. jordanis (BL-540) & + & ++++ & + \\
\hline
\end{tabular}

Digestion of egg yolk and lecithin

Seven species of Legionella were grown at $35^{\circ} \mathrm{C}$ on ABYE egg-yolk agar (Table 2). L. micdadei did not digest egg yolk. Apart from the absence of an iridescent sheen to the culture of $L$. dumoffi, presumptive lipase, protease and lecithinase reactions developed in the cultures of each of the other six species. L. bozemanii displayed the strongest presumptive lecithinase reaction.

Assessment of lecithinase activity on BYE agar incorporating approximately $1.8 \%, 0.60 \%$ or $0.47 \%(w / v) L-\alpha$-phosphatidylcholine was precluded by the inhibition of growth of these seven strains of Legionella on the lecithin-supplemented media. All seven species grew without formation of an opaque precipitate on BYE agar containing $0.49 \%(\mathrm{w} / \mathrm{v})$ potassium 2oxoglutarate and $0.29 \%(\mathrm{w} / \mathrm{v}) \mathrm{L}-\alpha$-phosphatidylcholine, but this medium contained less than one-tenth the concentration of lecithin conventionally used to detect microbial phospholipases (Chrisope et al., 1976).

\section{Hydrolysis of p-nitrophenylphosphorylcholine}

Within $2 \mathrm{~d}$ of inoculation of L. bozemanii on DBYE agar with p-nitrophenylphosphorylcholine, the medium developed a yellow cast, which progressively deepened over the ensuing $10 \mathrm{~d}$. Fainter yellowing of the medium occurred with growth of $L$. pneumophila but not with cultures of L. micdadei, L. dumoffi, L. gormanii, L. longbeachae or L. jordanis.

Suspensions of washed cells of all the strains tested produced detectable hydrolysis of $p$ nitrophenylphosphorylcholine (Table 3). As in the qualitative plate assay, phospholipase $C$ activity was greater with $L$. bozemanii than with other Legionella species. $C$. perfringens phospholipase $C$ hydrolysed the chromogenic substrate; two of three vegetable phospholipase $D$ preparations had lesser hydrolytic activity (Table 3 ). 
Table 3. Hydrolysis of p-nitrophenylphosphorylcholine by Legionella spp.

Results are given as mean \pm range of duplicate samples. Activity of $C$. perfringens phospholipase $C$ : $6.29 \pm 0.00 \mathrm{mmol} p$-nitrophenol liberated $U^{-1}$. Activities of reference phospholipases $D$ : peanut, type

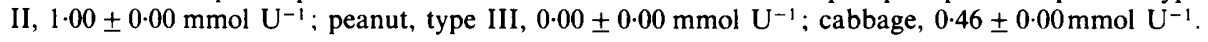

Species and strain

L. pneumophila (Philadelphia 1)
L. pneumophila (Dallas 1E)
L. bozemanii (Wiga)
L. micdadei (PI-1)
Expt 1
Expt 2
L. dumoffi (NY-23)
L. gormanii (LS-13)
L. longbeachae (Long Beach 4)
L. jordanis (BL-540)

p-Nitrophenol liberated

$\left(\mu \mathrm{mol}\right.$ per litre per $\mathrm{OD}_{590}$ unit of bacteria)

$$
\begin{array}{r}
15 \cdot 2 \pm 1 \cdot 3 \\
15 \cdot 3 \pm 0 \cdot 3 \\
247 \pm 3 \\
11 \cdot 1 \pm 0.5 \\
7 \cdot 4 \pm 0 \cdot 4 \\
5 \cdot 6 \pm 0.5 \\
17 \cdot 0 \pm 0.0 \\
12 \cdot 1 \pm 0.5 \\
7 \cdot 4 \pm 0.3
\end{array}
$$

Table 4. Hydrolysis of $\mathrm{L}-\alpha-$ dipalmitoyl[choline-methyl $\left.{ }^{3} H\right]$ phosphatidylcholine by Legionella spp. at $37^{\circ} \mathrm{C}$

Results are given as mean \pm range of duplicate samples. Activity of $C$. perfringens phospholipase $C$ : $41 \cdot 8 \pm 1 \cdot 0 \mathrm{nmol}\left[{ }^{3} \mathrm{H}\right]$ choline phosphate liberated $\mathrm{U}^{-1}$. Activities of reference phospholipases $D$ : peanut, type II, $-0 \cdot 3 \pm 0 \cdot 1 \mathrm{nmol} \mathrm{U} U^{-1}$; peanut, type III, $0.2 \pm 0.0 \mathrm{nmol} \mathrm{U} \mathrm{U}^{-1}$; cabbage, $1.2 \pm 0.2 \mathrm{nmol}$ $\mathrm{U}^{-1}$.

Species and strain

L. pneumophila (Philadelphia 1)

Expt 1

Expt 2

L. bozemanii (Wiga)

Expt 1

Expt 2

L. micdadei (PI-1)

L. dumoffii (NY-23)

L. longbeachae (Long Beach 4)

L. jordanis (BL-540)
Percentage of substrate hydrolysed

$$
\begin{array}{r}
99 \cdot 1 \pm 2 \cdot 0 \\
98 \cdot 6 \pm 5 \cdot 0 \\
14 \cdot 5 \pm 5 \cdot 2 \\
2 \cdot 8 \pm 0 \cdot 5 \\
0 \cdot 1 \pm 0 \cdot 1 \\
52 \cdot 7 \pm 6 \cdot 9 \\
4 \cdot 1 \pm 0 \cdot 2 \\
51 \cdot 7 \pm 5 \cdot 3
\end{array}
$$

\section{Hydrolysis of tritiated lecithin}

Extraction of label from the supernates of blanks containing no bacterial cells was $98 \cdot 4-98 \cdot 8 \%$ complete, indicating that the organic solvents effectively removed unmetabolized tritiated lecithin from the samples. Five of six Legionella species tested showed definite phospholipase $\mathrm{C}$ activity at $37^{\circ} \mathrm{C}$ (Table 4). Enzyme activity was markedly inhibited at $4{ }^{\circ} \mathrm{C}$ (data not shown). Only L. micdadei, which also exhibited minimal haemolysis (Table 1) and did not digest egg yolk (Table 2), gave no significant hydrolysis of labelled lecithin (Table 4). The specificity of the assay with tritiated lecithin was confirmed by the results obtained with $C$. perfringens phospholipase $\mathrm{C}$ and phospholipases $\mathrm{D}$ of vegetable origin (Table 4).

\section{DISCUSSION}

An intense outpouring of inflammatory cells into affected alveoli characterizes pneumonia caused by L. pneumophila. Cytoclasis with necrosis of mononuclear and polymorphonuclear cells in the inflammatory exudate occurs (Winn \& Myerowitz, 1981). This necrotizing process often yields small abscesses (Blackmon et al., 1981; Winn \& Myerowitz, 1981) and sometimes progresses to large cavities which are visible by roentgenography (Edwards \& Finlayson, 1980; Lewin et al., 1979; Magnussen \& Israel, 1980). 
Toxins produced in vivo by Legionella might damage alveolar cells or leucocytes in inflammatory infiltrates. An extracellular product of low molecular weight that is toxic to Chinese hamster ovary cells (Friedman et al., 1980) and that disrupts the oxidative metabolism of polymorphonuclear leucocytes (Friedman et al., 1982) has been isolated from L. pneumophila, but this substance apparently lacks cytolytic activity. L. pneumophila elaborates various proteases in vitro (Feeley et al., 1978; Baine et al., 1979a; Müller, 1981; Thompson et al., 1981; Thorpe \& Miller, 1981; Nolte et al., 1982; Berdal et al., 1983), but these enzymes are not likely to produce the leucocytoclasis and abscess formation seen in lungs infected with Legionella. A better candidate for a hypothetical product of Legionella organisms causing necrosis of inflammatory cells and pulmonary parenchyma would be a toxin acting on host cell membranes (Alouf, 1977).

The pathological effects of bacterial cytolysins are influenced by the anatomic site of infection. For example, profound intravascular haemolysis is produced by $\alpha$-toxin in Clostridium perfringens septicaemia (MacLennan, 1962), whereas $C$. perfringens pneumonia produces necrosis of lung tissue without haemolysis (Bayer et al., 1975). Erythrocytes are convenient target cells for the assay of bacterial cytolysins regardless of whether naturally acquired infections with a given pathogen cause intravascular infection and haemolysis.

Cultures of L. pneumophila show haemolytic activity (Baine et al., 1979a), and urine and plasma from rabbits experimentally infected with $L$. pneumophila lyse guinea-pig red blood cells in vitro (Baine et al., 1979b). Haemolytic activity has also been reported in supernates of cultures of L. pneumophila (Thorpe \& Miller, 1984) and L. bozemanii (Frisch \& Baine, 1984). This study demonstrates that cytolytic activity which is demonstrable in vitro with red blood cell targets is widespread in the genus Legionella.

Haemolytic cytolysins for which the mechanism of action is defined include surface-active agents, cholesterol-binding compounds, and phospholipases and related enzymes that hydrolyse phosphoglycerides and sphingomyelin (Arbuthnott, 1982). The haemolytic activity of some bacterial phospholipases C is well known (Möllby, 1978). Haemolysis induced by phospholipase $\mathrm{C}$ may be mediated by an increase in osmotic fragility resulting from enzymic modification of the red blood cell membrane (Taguchi et al., 1983).

The predominant lipids of mammalian red blood cells are cholesterol, phosphatidylethanolamine, phosphatidylcholine (lecithin) and sphingomyelin. Marked interspecies differences exist in the ratio of the latter two phospholipids (Lehninger, 1975). Differences in the ratio of phosphatidylcholine to sphingomyelin may account for differences in the susceptibility of red blood cells from various mammalian species to lysis by a given bacterial phospholipidhydrolysing toxin (Liu, 1977). Red blood cells from guinea-pigs have previously been found to be more susceptible to haemolysis by six strains of $L$. pneumophila than those from rabbits, sheep, horses or humans (Baine et al., 1979a). In the present study, red blood cells from dogs were lysed by Legionella strains even more readily than those from guinea-pigs. The red blood cell membranes in both dogs and guinea-pigs contain a high ratio of phosphatidylcholine to sphingomyelin. Sheep red blood cells, with a low ratio of membrane phosphatidylcholine to sphingomyelin (Turner et al., 1958), were only moderately susceptible to lysis by Legionella. However, the phospholipid composition of the red blood cell membrane is not the sole determinant of susceptibility to haemolysis by Legionella strains. Membranes of rabbit and human red blood cells are similar in phospholipid content (Turner et al., 1958), but there were marked differences in Legionella haemolytic activity against cells from these two species.

Phosphatidylcholine is not found in most prokaryotes but it is the most abundant phospholipid in cells of $L$. pneumophila (Finnerty et al., 1979). It would not therefore be surprising if Legionella species could produce enzymes that metabolize this substance. Cultures of L. pneumophila on agar with $5 \%$ egg yolk have previously been reported to produce clouding of the medium similar to that caused by lecithinase-positive species of Clostridium (Baine et al., $1979 a$ ). This observation has been confirmed by Thorpe \& Miller (1981) but they found no evidence of lecithinase in cultures on agar containing $3 \% \mathrm{~L}-\alpha$-phosphatidylcholine. However, concentrations of $L-\alpha$-phosphatidylcholine that are sufficient to permit assessment of lecithinase activity in plate assays appear to inhibit growth of Legionella. 
The presumptive lecithinase activity shown on egg-yolk agar by six of the seven Legionella species tested was confirmed by more specific assays of bacterial cell suspensions with $p$ nitrophenylphosphorylcholine and tritiated lecithin. Apparent discrepancies between activities using the chromogenic and radiolabelled substrates may imply differences in enzyme specificity for the diacylglycerol moiety of phosphatidylcholine. For example, the synthetic phosphatide $p$-nitrophenylphosphorylcholine can be regarded equally well as an analogue of phosphatidylcholine or of sphingomyelin. Variation in the extent of hydrolysis of tritiated lecithin between experiments with a given species and between experiments with different species may also have been influenced by incubation of the cells at concentrations of Triton X-100 that were close to those that in preliminary experiments were found to kill Legionella cells.

L. micdadei, which is genetically distant from other species of Legionella (Hébert et al., 1980), was atypical in its minimal haemolytic activity and failure to digest egg yolk and to hydrolyse tritiated lecithin. No definite association between relative haemolytic potency and apparent phospholipase $\mathrm{C}$ activity was apparent among the other Legionella species examined. This finding may reflect the merely semiquantitative assessment of haemolytic activity but it is also compatible with mediation of haemolysis by other substances in addition to, or instead of phospholipase $\mathrm{C}$ in at least some species of Legionella.

Intrapulmonary liberation of phospholipase $\mathrm{C}$ might not only damage host cell membranes but also compromise pulmonary compliance by hydrolysis of dipalmitoylphosphatidylcholine (Klaus et al., 1961), the chief constituent of lung surfactant (Scarpelli, 1968). Alveolar hyaline membrane formation has been reported in legionellosis (Winn \& Myerowitz, 1981), raising the question of whether damage to the surfactant layer occurs.

Lung tissue infected with $L$. pneumophila contains numerous bacteria within alveolar macrophages (Blackmon et al., 1981; Winn \& Myerowitz, 1981). Horwitz and colleagues have investigated the interaction between phagocytes and this pathogen. Like Listeria monocytogenes and Mycobacterium tuberculosis, $L$. pneumophila is a facultatively intracellular parasite, multiplying in vitro in unstimulated human monocytes (Horwitz \& Silverstein, 1980, 1981) and macrophages (Nash et al., 1982) under conditions that do not permit extracellular replication. Intracellular multiplication within human monocytes is associated with the failure of lysosomes to fuse with phagosomes laden with live Legionella, but phagosome-lysosome fusion is not inhibited in monocytes ingesting killed bacteria (Horwitz, 1983). Thus live L. pneumophila cells may produce a factor perturbing the phagosome membrane so that the phagocytic vacuole is no longer receptive to fusion with lysosomes.

Diacylglycerol, formed in the hydrolysis of phosphatidylcholine by phospholipase C, causes perturbation of the membranes of erythrocytes and mast cells (Allan et al., 1975, 1976; Kennerly et al., 1979; Sullivan, 1981). Ahkong et al. (1973) have shown that application of glyceryl dioleate to the exterior of hen erythrocytes suspended in buffer induces them to fuse. The consequences of elevating the diacylglycerol concentration in the interior of an intramonocytic phagosome are not known, but the question arises of whether perturbation of the vacuole membrane by intraphagosomal release of phospholipase $\mathrm{C}$ by Legionella organisms could interfere with phagosome-lysosome fusion. Phospholipase $\mathrm{C}$ from $C$. perfringens has also been shown to inhibit chemotactic migration of human monocytes (Wilkinson, 1975), possibly by reducing binding of chemotactic substances to the phagocytes (Wilkinson \& Allan, 1978).

Although this study does not establish that haemolytic species of Legionella necessarily produce extracellular haemolysins, progress in the purification of haemolytic cytolysins from culture supernates of L. pneumophila (Thorpe \& Miller, 1984) and L. bozemanii (Frisch \& Baine, 1984 ) has already been reported. Further work is necessary to establish the optimal conditions for production of cytolysins and phospholipases $\mathrm{C}$ by various species of Legionella, to purify and characterize these products, and to evaluate the contribution of phospholipase $\mathrm{C}$ activity to haemolytic potency in each species. To assess the significance of haemolytic cytolysins and phospholipases $C$ in the pathogenesis of legionellosis, it will be useful to generate mutants deficient in one or both activities for comparison with wild-type strains in laboratory models of virulence and phagocytosis. 
This work was presented in part at the 2 nd International Symposium on Legionella, held in Atlanta, Georgia, on June 19-23, 1983.

This study was supported by Biomedical Research Support Grant 2 S07 RR05426-20 from the National Institutes of Health.

I thank Edward K. Davis for his capable technical assistance, George W. Gorman for generous material support, and Robert S. Munford for his astute criticism.

\section{REFERENCES}

AhKong, Q. F., Fisher, D., TAMPION, W. \& Lucy, J. A. (1973). The fusion of erythrocytes by fatty acids, esters, retinol and $\alpha$-tocopherol. Biochemical Journal 136, 147-155

Allan, D., Low, M. G., Finean, J. B. \& Michell, R. H. (1975). Changes in lipid metabolism and cell morphology following attack by phospholipase $\mathrm{C}$ (Clostridium perfringens) on red cells or lymphocytes. Biochimica et biophysica acta 413, 309-316.

Allan, D., Billah, M. M., Finean, J. B. \& Michell, R. H. (1976). Release of diacylglycerol-enriched vesicles from erythrocytes with increased intracellular $\left[\mathrm{Ca}^{2+}\right]$. Nature, London 261, 58-60.

Allen, S. D. \& Siders, J. A. (1980). Procedures for isolation and characterization of anaerobic bacteria. In Manual of Clinical Microbiology, 3rd edn, pp. 397417. Edited by E. H. Lennette, A. Balows, W. J. Hausler, Jr \& J. P. Truant. Washington, DC: American Society for Microbiology.

Alouf, J. E. (1977). Cell membranes and cytolytic bacterial toxins. In The Specificity and Action of Animal, Bacterial and Plant Toxins, pp. 219-270. Edited by P. Cuatrecasas. London: Chapman \& Hall.

ARbuthnotT, J. P. (1982). Bacterial cytolysins (membrane-damaging toxins). In Molecular Action of Toxins and Viruses, pp. 107-129. Edited by P. Cohen \& S. Van Heyningen. Amsterdam: Elsevier Biomedical Press.

Avigad, G. (1976). Microbial phospholipases. In Mechanisms in Bacterial Toxinology, pp. 99-167. Edited by A. W. Bernheimer. New York: John Wiley \& Sons.

Baine, W. B., Rasheed, J. K., Mackel, D. C., Bopp, C. A., Wells, J. G. \& Kaufmann, A. F. (1979a). Exotoxin activity associated with the Legionnaires disease bacterium. Journal of Clinical Microbiology 9 , 453-456.

Baine, W. B., Rasheed, J. K., Maca, H. W. \& KaufmanN, A. F. $(1979 b)$. Hemolytic activity of plasma and urine from rabbits experimentally infected with Legionella pneumophila. Reviews of Infectious Diseases 1, 912-917.

Bayer, A. S., Nelson, S. C., Galpin, J. E., Chow, A. W. \& GUzE, L. B. (1975). Necrotizing pneumonia and empyema due to Clostridium perfringens. American Journal of Medicine 59, 851-856.

Berdal, B. P., Bøvre, K., Olsvik, Ø. \& Omland, T. (1983). Patterns of extracellular proline-specific endopeptidases in Legionella and Flavobacterium spp. demonstrated by use of chromogenic peptides. Journal of Clinical Microbiology 17, 970-974.

Blackmon, J. A., Chandler, F. W., Cherry, W. B., England, A. C., III, Feeley, J. C., Hicklin, M. D., MCKinNEY, R. M. \& WiLKINSON, H. W. (1981).
Legionellosis. American Journal of Pathology 103, 427-465.

Chrisope, G. L., Fox, C. W. \& Marshall, R. T. (1976). Lecithin agar for detection of microbial phospholipases. Applied and Environmental Microbiology 31, 784-786.

EDwards, D. \& Finlayson, D. M. (1980). Legionnaires' disease causing severe lung abscesses. Canadian Medical Association Journal 123. 524-527.

Feeley, J. C., Gorman, G. W., Weaver, R. E., MACKel, D. C. \& SMith, H. W. (1978). Primary isolation media for Legionnaires disease bacterium. Journal of Clinical Microbiology 8, 320-325.

Feeley, J. C., Gibson, R. J., Gorman, G. W., LANGFoRd, N. C., RASHEED, J. K., MACKel, D. C. \& BAINE, W. B. (1979). Charcoal-yeast extract agar: primary isolation medium for Legionella pneumophila. Journal of Clinical Microbiology 10, 437-441.

Finnerty, W. R., Makula, R. A. \& Feeley, J. C. (1979). Cellular lipids of the Legionnaires' disease bacterium. Annals of Internal Medicine 90, 631-634.

Friedman, R. L., IglewsKi, B. H. \& Miller, R. D. (1980). Identification of a cytotoxin produced by Legionella pneumophila. Infection and Immunity 29, 271-274.

Friedman, R. L., Lochner, J. E., Bigley, R. H. \& IGLEWSKI, B. H. (1982). The effects of Legionella pneumophila toxin on oxidative processes and bacterial killing of human polymorphonuclear leukocytes. Journal of Infectious Diseases 146, 328-334.

Frisch, C. F. \& Baine, W. B. (1984). Production of extracellular hemolytic cytotoxin by Legionella bozemanii. Microbiology and Immunology 28, 1267-1272.

Grossman, S., Oestreicher, G., Hogue, P. K., COBleY, J. G. \& Singer, T. P. (1974). Microanalytical determination of the activities of phospholipases A, C, and D and of their mixtures. Analytical Biochemistry 58, 301-309.

Gulewirsch, W. (1898). Über Cholin und einige Verbindungen desselben. Zeitschrift für Physiologische Chemie 24, 513-541.

Hébert, G. A., Steigerwalt, A. G. \& Brenner, D. J. (1980). Legionella micdadei species nova: classification of a third species of Legionella associated with human pneumonia. Current Microbiology 3, 255-257.

Horwitz, M. A. (1983). The Legionnaires' disease bacterium (Legionella pneumophila) inhibits phagosome-lysosome fusion in human monocytes. Journal of Experimental Medicine 158, 2108-2126.

Horwitz, M. A. \& Silverstein, S. C. (1980). Legionnaires' disease bacterium (Legionella pneumophila) multiplies intracellularly in human monocytes. Journal of Clinical Investigation 66, 441-450.

Horwitz, M. A. \& Silverstein, S. C. (1981). Interaction of the Legionnaires' disease bacterium 
(Legionella pneumophila) with human phagocytes. II. Antibody promotes binding of $L$. pneumophila to monocytes but does not inhibit intracellular multiplication. Journal of Experimental Medicine 153, 398406.

Kennerly, D. A., Sullivan, T. J., Sylwester, P. \& PARKER, C. W. (1979). Diacylglycerol metabolism in mast cells: a potential role in membrane fusion and arachidonic acid release. Journal of Experimental Medicine 150, 1039-1044.

Klaus, M. H., Clements, J. A. \& Havel, R. J. (1961). Composition of surface-active material isolated from beef lung. Proceedings of the National Academy of Sciences of the United States of America 47, 18581859.

Kurioka, S. \& Matsuda, M. (1976). Phospholipase $C$ assay using $p$-nitrophenylphosphorylcholine together with sorbitol and its application to studying the metal and detergent requirement of the enzyme. Analytical Biochemistry 75, 281-289.

LeHNinger, A. L. (1975). Biochemistry, 2nd edn, p. 303. New York: Worth Publishers.

Lewin, S., Brettman, L. R., Goldstein, E. J. C., Holzman, R. S., Devila, H., Taubman, F., Sierra, M. F. \& Edelstein, P. H. (1979). Legionnaires' disease: a cause of severe abscess-forming pneumonia. American Journal of Medicine 67, 339-342.

LiU, P. V. (1977). Exotoxins of gram-negative bacteria exclusive of enterotoxins. In Perspectives in Toxinology, pp. 43-60. Edited by A. W. Bernheimer. New York: John Wiley \& Sons.

Maclennan, J. D. (1962). The histotoxic clostridial infections of man. Bacteriological Reviews 26, 177 276.

Magnussen, C. R. \& Israel, R. H. (1980). Legionnaires' lung abscess. American Journal of the Medical Sciences 279, 117-120.

MEYER, R. D. (1983). Legionella infections: a review of five years of research. Reviews of Infectious Diseases 5, 258-278.

MöllBy, R. (1978). Bacterial phospholipases. In Bacterial Toxins and Cell Membranes, pp. 367-424. Edited by J. Jeljaszewicz \& T. Wadström. New York: Academic Press.

MÜLLER, H. E. (1981). Enzymatic profile of Legionella pneumophila. Journal of Clinical Microbiology 13, $423-426$

NASH, T. W., LibBy, D. M. \& Horwitz, M. A. (1982). Legionnaires' disease bacteria multiply in human alveolar macrophages (AM) and activated alveolar macrophages inhibit multiplication [abstract no. 93]. In Program and Abstracts of the 22nd Interscience Conference on Antimicrobial Agents and Chemotherapy'. Washington, DC: American Society for Microbiology.

Nolte, F. S., Hollick, G. E. \& Robertson, R. G. (1982). Enzymatic activities of Legionella pneumo- phila and Legionella-like organisms. Journal of Clinical Microbiology 15, 175-177.

Pasculle, A. W., Feeley, J. C., Gibson, R. J., Cordes, L. G., Myerowitz, R. L., Patton, C. M., Gorman, G. W., Carmack, C. L., Ezzell, J. W. \& Dowling, J. N. (1980). Pittsburgh pneumonia agent: direct isolation from human lung tissue. Journal of Infectious Diseases 141, 727-732.

Renshaw, R. R. (1910). Preparation of choline and some of its salts. Journal of the American Chemical Society 32, 128-130.

SCARPELli, E. M. (1968). The Surfactant System of the Lung, p. 269. Philadelphia: Lea \& Febiger.

Smith, L. DS., Dowell, V. R., JR \& Allen, S. D. (1980). Clostridium. In Manual of Clinical Microbiology, 3rd edn, pp. 418-425. Edited by E. H. Lennette, A. Balows, W. J. Hausler, Jr \& J. P. Truant. Washington, DC: American Society for Microbiology.

Sullivan, T. J. (1981). Diacylglycerol metabolism and the release of mediators from mast cells. In Biochemistry of the Acute Allergic Reactions, pp. 229-238. Edited by E. L. Becker, A. S. Simon \& K. F. Austen. New York: Alan R. Liss.

Taguchi, R., Mizuno, M., Inoue, M. \& Ikezawa, H. (1983). Increase in osmotic fragility of bovine erythrocytes induced by bacterial phospholipases $C$. Journal of Biochemistry 93, 403-412.

Thompson, M. R., Miller, R. D. \& Iglewski, B. H. (1981). In vitro production of an extracellular protease by Legionella pneumophila. Infection and Immunity 34, 299-302.

ThORPe, T. C. \& Miller, R. D. (1981). Extracellular enzymes of Legionella pneumophila. Infection and Immunity 33, 632-635.

ThORPE, T. C. \& Miller, R. D. (1984). Characterization of an extracellular hemolysin from Legionella pneumophila. In Legionella: Proceedings of the 2nd International Symposium, pp. 97-98. Edited by C. Thornsberry, A. Balows, J. C. Feeley \& W. Jakubowski. Washington, DC: American Society for Microbiology.

Turner, J. C., Anderson, H. M. \& Gandal, C. P. (1958). Species differences in red blood cell phosphatides separated by column and paper chromatography. Biochimica et biophysica acta 30, 130-134.

WILKINSON, P. C. (1975). Inhibition of leukocyte locomotion and chemotaxis by lipid-specific bacterial toxins. Nature, London 255, 485-487.

Wilkinson, P. C. \& Allan, R. B. (1978). Binding of protein chemotactic factors to the surfaces of neutrophil leukocytes and its modification with lipid-specific bacterial toxins. Molecular and Cellular Biochemistry 20, 25-40.

WINN, W. C., JR \& Myerowitz, R. L. (1981). The pathology of the Legionella pneumonias. Human Pathology 12, 401-422. 